\title{
Correction to: Tripartite motif 31 alleviates IL-1ß secretion via promoting the ubiquitination of pyrin domain domains-containing protein 3 in human periodontal ligament fibroblasts
}

\author{
Xueying $\mathrm{Wu}^{1} \cdot$ Mengmeng $\mathrm{Lu}^{2} \cdot$ Sheng Ding ${ }^{3}$. Qun Zhong ${ }^{1}$
}

Published online: 12 May 2020

(c) The Society of The Nippon Dental University 2020

\section{Correction to: Odontology \\ https://doi.org/10.1007/s10266-020-00519-7}

The article Tripartite motif 31 alleviates IL $1 ß$ secretion via promoting the ubiquitination of pyrin domain domains containing protein 3 in human periodontal ligament fibroblasts, written by Xueying Wu, Mengmeng Lu, Sheng Ding and Qun Zhong, was originally published electronically on the publisher's internet portal (currently SpringerLink) on 22 April 2020 with open access. With the author(s)' decision to step back from Open Choice, the copyright of the article changed on 7 May 2020 to (C) The Society of The Nippon
Dental University 2020 and the article is forthwith distributed under the terms of copyright.

The original article was updated.

Publisher's Note Springer Nature remains neutral with regard to jurisdictional claims in published maps and institutional affiliations.
The original article can be found online at https://doi.org/10.1007/ s10266-020-00519-7.

\section{Qun Zhong}

yongjialu458@163.com

1 Yongjia Clinic, Shanghai Stomatological Hospital, Fudan University, No. 458 Yongjia Road, Shanghai 200031, China

2 Department of Oral and Maxilofacial Surgery, Shanghai Stomatological Hospital, Fudan University, 1258 Middle Fuxing Road, Shanghai 200031, China

3 Department of Stomatology, Xinhua Hospital Affiliated To Shanghai Jiaotong University of Medicine, 1665 Kongjiang Road, Shanghai 200092, China 